\title{
Assessment of the knowledge, attitude and practice of EC and barriers to its use among the antenatal care seekers of Sululta Health Centers, Oromia region, Ethiopia
}

\author{
Mekonnen Seifu, Fanta Gashe, Awol Jemal, Shibiru Tessema, Wote Amelo* \\ Department of Pharmacy, College of Public Health and Medical Sciences, Jimma University, Ethiopia \\ Received: 21 January 2016 \\ Revised: 25 January 2016 \\ Accepted: 16 February 2016 \\ *Correspondence: \\ Mr. Wote Amelo \\ E-mail: wote.amelo@ju.edu.et \\ Copyright: (c) the author(s), publisher and licensee Medip Academy. This is an open-access article distributed under \\ the terms of the Creative Commons Attribution Non-Commercial License, which permits unrestricted non-commercial \\ use, distribution, and reproduction in any medium, provided the original work is properly cited.
}

\begin{abstract}
Background: With global expansion of contraceptive information and services, contraceptive technologies have continually improved and contraceptive prevalence has risen throughout most of the world. Emergency contraceptive pills have become more available in many developing countries. However, limited provider knowledge and negative attitudes, as well as poor user awareness and access, have hindered clients in learning about and using it. The aim of the present study is to assess the knowledge, attitude and practice of EC and also barriers to its use among the antenatal care attendees of Sululta health centers.

Methods: A cross sectional study was conducted in Sululta health centres from January to February 2013/2014. Eighty seven Antenatal care attendees were interviewed. Pretested and structured questionnaire was used to collect data.

Results: Of the 87 women included in the study $23(26.4 \%)$ reported that the current pregnancy was unplanned and 5 $(5.7 \%)$ reported that they had induced abortion in the previous years. Of the study participants $25(28.7 \%)$ had ever heard about EC. Whereas only $6(6.9 \%)$ of the women had actually used EC. The preferred places for the provision of EC were public hospitals $2(8 \%)$, health centers $17(68 \%)$, private clinics $3(12 \%) \&$ pharmacies $11(44 \%)$.

Conclusions: This study showed that the major barrier to the use of EC is lack of awareness \& also there is demand for education.
\end{abstract}

Keywords: Emergency contraception (EC), Attitude, Knowledge, Practice, Pregnant women

\section{INTRODUCTION}

With global expansion of contraceptive information and services, contraceptive technologies have continually improved and contraceptive prevalence has risen throughout most of the world. However, access to mainstream contraceptive methods is more limited in sub-Saharan Africa than elsewhere; on average contraceptive prevalence in Africa is approximately $27 \%$, less than half the average throughout the world. ${ }^{1}$ Emergency contraception (EC) is a method to prevent pregnancy after an unprotected act of sexual intercourse and before the potential time of implantation. ${ }^{2}$ It is well established that many unintended pregnancies occur as a result of unprotected intercourse, inadequate contraceptive measures or failure of a method. So, effective method of post-coital or EC can prevent many of these pregnancies (75-89\%) as well as the health and the social consequences associated with them. ${ }^{3}$ Many of the unintended pregnancies go for abortions which are performed in unsafe condition incurring the higher risk of morbidity and mortality. Also unwanted births can be detrimental to children's health and well being. ${ }^{4}$ 
Complications of unsafe abortions also take a huge toll on maternal survival. The World Health Organization (WHO) estimated that in the developing countries one woman dies every eight minutes due to unsafe abortions. ${ }^{5}$ In total, twenty million unsafe abortions take place globally each year, endangering the lives of women who undergo these procedures in unhealthy surroundings with untrained providers. Abortion-related maternal deaths total almost seventy thousand annually, and most of these procedures could be avoided if family planning services were easily accessible to women. ${ }^{6}$

In Ethiopia, unwanted pregnancy is a big problem; more than $60 \%$ of the pregnancies in adolescents are unwanted resulting from unprotected sexual intercourse which is an alarming figure, and most of these pregnancies particularly in adolescents end up with unsafe abortion. In about half of all unwanted pregnancies, conception and unsafe abortion occurring in the country is due to inadequate guidance to use contraception effectively, including the users' inability to address their feelings, poor attitudes towards contraceptives, and lack of motivations. $^{7}$ In 2005 , only $15 \%$ of married women used contraception and in turn a 5.4 total fertility rate was recorded in the same year. More than two in five births to mothers who were age 45-49 at the time of the birth were not planned compared with one in ten births to mothers age 25 or younger. ${ }^{8,9}$

EC takes two forms: the administration of emergency contraceptive pills (ECPs), which contain high doses of female sex hormones, or the insertion of a copper Intra uterine device (IUD) in the uterus. ${ }^{10}$ Levenorgestrel only pill and combined oral contraceptives are the most common emergency contraceptives available in Ethiopia. ${ }^{11}$ Formerly, EC was thought to be effective only within 72 hours, but recent studies have confirmed it is effective for up to 120 hours. Effectiveness of emergency contraceptive pills is $75 \%-89 \%$ when taken within 72 hours of unprotected intercourse. When taken within 72 hours of unprotected intercourse, ECPs that contain both estrogen and progestin reduces the risk of pregnancy by 75 percent. When initiated within 24 hours of unprotected intercourse, progestin-only ECPs were found to reduce the risk of pregnancy by 95 percent. The copper releasing intrauterine device (IUD) can be used safely for EC up to 5 days after unprotected intercourse, reducing the risk of pregnancy by over $99 \% .^{12,13}$

EC was first introduced in Ethiopia in 1997 and April of 2008, DKT Ethiopia introduced an EC brand called Postpill, available over-the-counter at pharmacies and private clinics. ${ }^{14}$ So, it is distributed in the commercial sector by DKT-Ethiopia, a social marketing organization. However, provider related barriers, as well as poor user awareness and access, have hindered clients in learning about and using ECPs. ${ }^{15}$ Reported Provider-related barriers include low levels of knowledge, negative or biased attitudes, and restrictive distribution practices directly limit availability and which inturn negatively affect access to and utilization of EC. ${ }^{16}$

Most couples do not want to use a contraceptive method on a long-term basis hence unwanted and unplanned pregnancies are common. ${ }^{17}$ There is little knowledge about why women of reproductive age for whom EC is indicated make no use of it. Some forwarded reasons are low knowledge of EC, extreme age groups, low educational level, having had children and having experienced a previous abortion are all associated with EC non-use. ${ }^{18}$ From the study conducted in Jimma University Specialized Hospital from 89 women interviewed only nine women had awareness about emergency contraceptive. All of them have positive attitude towards EC but none of them have ever used emergency contraceptives. ${ }^{11}$ Misinformation about EC, false claims about their safety and efficacy exist in many places. This undermines EC's ability to improve sexual health of women. ${ }^{19,20}$

So far limited studies have been conducted on the issue of EC in Ethiopia which mainly focused on highschool, college and University students. But it is also important to determine the level of knowledge, attitude and practice (KAP) on EC particularly for women from rural area where the chance of getting information on sexual and reproductive health is limited. So the aim of the present study is to assess the knowledge, attitude and practice of EC \& also barriers to its use among the antenatal care attendees of Sululta health centres.

\section{METHODS}

The study was conducted in Sululta Health Centres in Sululta wereda which is located $15 \mathrm{~km}$ north of Addis Ababa, Ethiopia. The health centres are providing several health services for the community. The study was conducted from January 24 to February 9, 2014.

Health institution based cross sectional quantitative study design was used. The source population was Women of reproductive age group (15-49) visiting the Antenatal care clinics of the Sululta health centres for routine ANC check-ups during the data collection period. The study population was those women who were attending ANC follow up during study period and fulfil the inclusion criterion.

\section{Inclusion criteria}

women who were residents of Sululta and nearby, women aged 15-49 years who came to the health centres for regular ANC follow up.

\section{Exclusion criteria}

Hearing problem, not regular residents of Sululta and surroundings, pregnant women not coming for ANC follow up, mentally and clinically unstable. 
The study was conducted using a convenience sampling technique. Clients found during the study period at the study area who fulfil the inclusion criteria were included in the study.

The data was collected by interview using closed ended questionnaire. The questionnaire was adapted from published work, which was prepared in English and some modification was done based on the objectives of this particular study. ${ }^{21}$ Then it was translated to local languages (Amharic and Afan Oromo) since the study subjects mostly speak these languages. The questionnaire was then translated back to English to check for consistency. Every day the collected data was reviewed and checked for completeness and consistency of response.

Data was analyzed using windows SPSS version 16.0. Descriptive analysis was performed and association was identified for categorical data using Pearson Chi-square test. $\mathrm{P}$ value of $\leq 0.05$ was considered as statistically significant.

Ethical clearance was obtained from the Ethical Review Board of Jimma University, College of Public Health and Medical Science department of pharmacy. Then officials at different levels in the study area were communicated through letters from Jimma University, College of Public Health and Medical Science department of pharmacy. Informed consent was obtained verbally from each study participant after clear explanation about the purpose of the study. Confidentiality of the information was assured and privacy of the respondents was maintained.

\section{RESULTS}

Age of the study subjects range from 16-45 years. Educational level of $61(70.1 \%)$ of the interviewed antenatal care attendees varies from primary school to higher education, while 26(29.9\%) were illiterate. Among the study subjects $62(71.4 \%)$ were Orthodox Christians followed by protestants $13(14.9 \%)$ and Muslims 9 (10.3\%). From the total respondents 54 (62.1\%) were housewives (Table 1).

Majority $(81.6 \%)$ of study participants were married women (Figure 1).

\section{Regular contraception use}

Majority of respondents, $71(81.6 \%)$ were above 18 years of age during the first pregnancy and the remaining 16 $(18.4 \%)$ were under 18 years of age. Reported number of pregnancies including the present one were once, 12 $(13.8 \%)$, twice, $32(36.8 \%)$ and more than three times 43 $(49.4 \%)$.

Among the study participants, 31 (35.6\%), had never ever used any form of regular contraceptive methods. Sixty four $(73.6 \%)$ of the study participants claimed that the pregnancy was planned and the remaining unwanted/unplanned. The major reasons specified for not using contraception among those who had unplanned or unwanted pregnancies were, forgetting to take $8(34.8 \%)$, contraceptive failure $5(21.7 \%)$ and do not know about contraceptive $5(21.7 \%)$ (Table 2$)$.

Table 1: Socio demographic Characteristics of women seeking Antenatal Care in Sululta health centers North Shewa, Ethiopia from January 24-February 9 2014.

\begin{tabular}{|ll|}
\hline Variable & $\mathbf{N}(\%)$ \\
\hline Age & \\
\hline $16-19$ & $3(3.4)$ \\
\hline $20-24$ & $16(18.4)$ \\
\hline $25-29$ & $22(25.3)$ \\
\hline $30-34$ & $28(32.2)$ \\
\hline $35-39$ & $11(12.6)$ \\
\hline $40-45$ & $7(8.1)$ \\
\hline Educational Status & \\
\hline Can't read and write & $26(29.9)$ \\
\hline Can read and write & $31(35.6)$ \\
\hline Primary (1-8) & $3(3.4)$ \\
\hline Secondary (9-12) & $12(13.8)$ \\
\hline Higher Education & $15(17.3)$ \\
\hline Religion & \\
\hline Orthodox & $62(71.4)$ \\
\hline Muslim & $9(10.3)$ \\
\hline Protestant & $13(14.9)$ \\
\hline Others & $3(3.4)$ \\
\hline Occupation & \\
\hline Housewife & $54(62.1)$ \\
\hline Daily labourer & $16(18.4)$ \\
\hline Office worker & $2(2.3)$ \\
\hline Factory worker & $5(5.7)$ \\
\hline Student & $2(2.3)$ \\
\hline Teacher & $6(6.9)$ \\
\hline Other & $2(2.3)$ \\
\hline Family Monthly Income & $12(13.8)$ \\
\hline$<150$ & $18(29.9)$ \\
\hline $150-249$ & \\
\hline $250-499$ & \\
\hline $500-999$ & \\
\hline 1000 \& above & \\
\hline no response & \\
\hline
\end{tabular}

According to this study relatively more experience was reported on using oral contraceptive pills (39.1\%) and injections (33.3\%) than others (Figure 2).

\section{Awareness and utilization of $E C$}

About 25 (28.7\%) of the study subjects heard about EC and they were asked the knowledge assessment questions. Accordingly, $19(76 \%)$ of the participants answered correctly when to take EC after unprotected sex, 13 
(52\%) answered the question on Effectiveness of EC, 12 (53\%) answered correctly the question on the side effects of $\mathrm{EC}$, for the question what are the sources for EC, 19 $(76 \%)$ of the respondents said government hospitals and government health centres, 11 (44\%) pharmacy, $3(12 \%)$ private health institutions \& $5(20 \%)$ of the respondents answered correctly for the question whether EC can work if there is menstrual delay (Table 3).

Table 2: Reproductive characteristics of antenatal care clients in Sululta health centres North Shewa,

Ethiopia from January 24-February 9, 2014.

\begin{tabular}{|c|c|}
\hline Variables & $\mathbf{N}(\%)$ \\
\hline \multicolumn{2}{|l|}{ Age at first marriage } \\
\hline$<18$ year & $16(18.4)$ \\
\hline$>18$ year & $71(81.6)$ \\
\hline \multicolumn{2}{|l|}{ No. of pregnancies including the current } \\
\hline Once & $12(13.8)$ \\
\hline Twice & $32(36.8)$ \\
\hline$>3$ times & $43(49.4)$ \\
\hline \multicolumn{2}{|l|}{ Current pregnancy planned } \\
\hline Yes & $64(73.6)$ \\
\hline No & $23(26.4)$ \\
\hline \multicolumn{2}{|c|}{ Reason for the unplanned/unwanted pregnancy } \\
\hline Forget to take contraceptive pills & $8(34.8)$ \\
\hline Contraceptive failure & $5(21.7)$ \\
\hline Pressure from partner & $1(4.4)$ \\
\hline Concern about contraceptive side effect & $2(8.7)$ \\
\hline Don't know about contraceptive & $5(21.7)$ \\
\hline No response & $2(8.7)$ \\
\hline \multicolumn{2}{|l|}{ Ever used contraceptives } \\
\hline Yes & $56(64.4)$ \\
\hline No & $31(35.6)$ \\
\hline \multicolumn{2}{|l|}{ Ever heard about EC } \\
\hline Yes & $25(28.7)$ \\
\hline No & $62(71.3)$ \\
\hline \multicolumn{2}{|l|}{ Ever used EC } \\
\hline Yes & $6(6.9)$ \\
\hline No & $81(93.1)$ \\
\hline
\end{tabular}

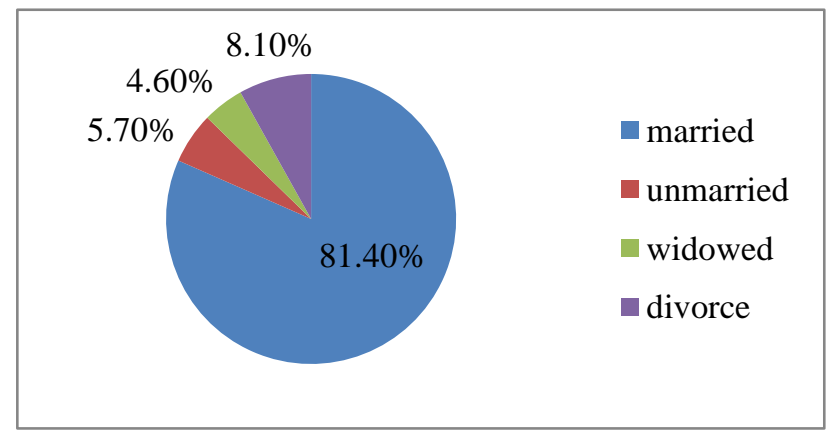

Figure 1: Marital status of the study participants in Sululta health centres North Shewa, Ethiopia from January 24- February 9, 2014.
Table 3: Awareness and utilization of EC among antenatal care clients in Sululta health centres North Shewa, Ethiopia from January 24-February 9, 2014.

\begin{tabular}{|c|c|}
\hline Variable & $\mathbf{N}(\%)$ \\
\hline \multicolumn{2}{|l|}{ Ever heard about EC } \\
\hline Places from where ECPs obtained & $25(28.7)$ \\
\hline Public health centres & $17(68 \%)$ \\
\hline Public hospitals & $2(8)$ \\
\hline Pharmacy & 11(44) \\
\hline Private health institution & $3(12)$ \\
\hline \multicolumn{2}{|l|}{ ECs work if there is menstrual delay } \\
\hline Yes & $5(20)$ \\
\hline No & $9(36)$ \\
\hline I don't know & $11(44)$ \\
\hline \multicolumn{2}{|c|}{$\begin{array}{l}\text { Time at which ECs should be taken after unprotected } \\
\text { sex }\end{array}$} \\
\hline Immediately after unprotected sex & $7(28)$ \\
\hline Within 72 hours & $9(36)$ \\
\hline Within 120 hours & $2(8)$ \\
\hline $\begin{array}{l}\text { At any time before the first day of } \\
\text { unprotected sex }\end{array}$ & $3(12)$ \\
\hline I don't know & $4(16)$ \\
\hline \multicolumn{2}{|c|}{ Effectiveness of EC in preventing pregnancy } \\
\hline Very good & $5(20)$ \\
\hline good & $8(32)$ \\
\hline Fair & $2(8)$ \\
\hline Not sure & $10(40)$ \\
\hline \multicolumn{2}{|l|}{ Side effects of $E C$} \\
\hline Don't cause any health problem(very safe) & $5(25)$ \\
\hline Safe & $7(28)$ \\
\hline Cause health problem & $3(12)$ \\
\hline Not sure & $10(40)$ \\
\hline \multicolumn{2}{|l|}{ Reason for using $E C$} \\
\hline Condom broke or slipped & $4(16)$ \\
\hline Pills missed & $12(48)$ \\
\hline The timing miscalculated & $6(24)$ \\
\hline Withdrawal failed & $2(8)$ \\
\hline Contraception not used & $5(25)$ \\
\hline
\end{tabular}

NB. The knowledge assessment questions and also practices about EC were asked only for those who have ever heard about EC so in this table the total number (n) is 25 . *percentage might add up more than $100 \%$, because more than one answer was possible.

\section{Attitude of the study subjects toward EC}

From 25 women who heard about EC, 9 (36\%) had no questions and concerns about contraception but 16(64\%) of them expressed their concerns about EC: 2 (8\%) said EC may cause health problems, $5(20 \%)$ said it may hurt the fetus if it doesn't work, $3(12 \%)$ said it may result in complications to get pregnant in the future, $1(4 \%)$ if men know this method exists they will exert pressure on women to use it, $3(12 \%)$ it will result in more women suffering from STI and even HIV (Table 4) 


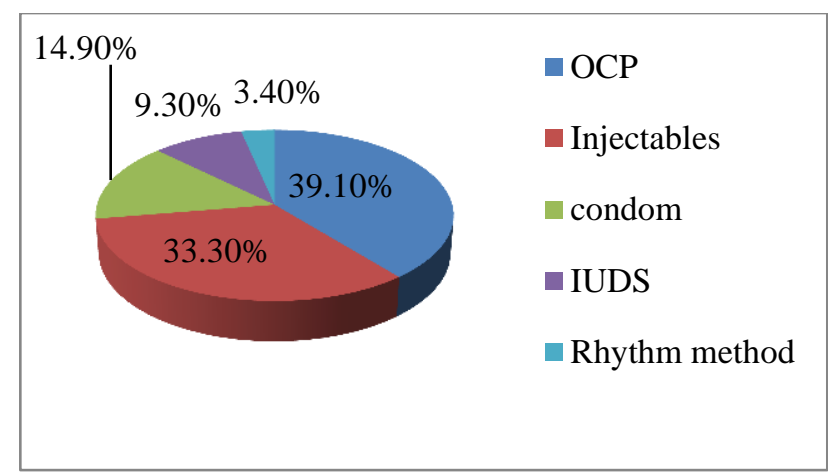

Figure 2: Contraceptive methods ever known and used by the attendants in Sululta health centres North Shewa, Ethiopia from January 24- February 9, 2014.

Table 4: Attitude of women seeking Antenatal care toward EC in Sululta health centres North Shewa, Ethiopia from January 24-February 9, 2014.

\begin{tabular}{|lc|}
\hline Variable & $\mathbf{N}(\%)$ \\
\hline Concerns toward $\boldsymbol{E C}$ & $16(64)$ \\
\hline Yes & $9(36)$ \\
\hline No & \\
\hline Concerns about $\boldsymbol{E C}$ & $2(8)$ \\
\hline I don't have enough information about it & $5(20)$ \\
\hline May cause health problem & $3(12)$ \\
\hline Hurt the fetus if it doesn't work & $1(4)$ \\
\hline $\begin{array}{l}\text { May result in problem to get pregnant } \\
\text { in the future }\end{array}$ & $3(12)$ \\
\hline $\begin{array}{l}\text { If men knows the presence of ECPs } \\
\text { they would enforce women to use it }\end{array}$ & $\begin{array}{l}\text { Makes women to suffer from STI even } \\
\text { HIV/AIDS }\end{array}$ \\
\hline
\end{tabular}

\section{Determinants of awareness about EC}

In Table 5, education and income of the family have significant association with awareness of emergency contraceptives.

\section{DISCUSSION}

In the present day scenario of population explosion, family planning has been the most important national issue; and knowledge, attitude \& practice studies have a deciding role to play in it. As one of the contraception method, EC is the most useful method after unprotected sexual intercourse and failure of barrier methods such as slippage and breakage of condoms to reduce the chance of unwanted pregnancies. ${ }^{2,22}$

According to our study, $23(26 \%)$ of the pregnancies were unplanned. The commonest reason for occurrence of unplanned pregnancies among the study subjects were forgetting to take contraceptive pills 8 (35\%) \& contraceptive method failure $5(22 \%)$. Five $(5.7 \%)$ of the study participants had history of induced abortion in the previous years. The possible reason for this could be awareness gap regarding the presence of EC for such cases.

Table 5: Determinants of awareness of EC among women seeking Antenatal care in Sululta health centres North Shewa, Ethiopia from January 24February 9, 2014.

\begin{tabular}{|llll|}
\hline Variable & \multicolumn{2}{c|}{ Awareness } & P-value \\
\hline Age & Yes & No & \\
\hline $16-29$ & 14 & 27 & 0.950 \\
\hline $30-45$ & 16 & 30 & \\
\hline Education & & & \\
\hline No formal Education & 7 & 42 & \\
\hline Grade 1-8th & 1 & 2 & 0.000 \\
\hline Grade 9th \& above & 18 & 9 & \\
\hline Religion & & & \\
\hline Orthodox & 25 & 37 & \\
\hline Muslim & 2 & 7 & 0.712 \\
\hline Protestant & 4 & 9 & \\
\hline Others & 1 & 2 & \\
\hline Income & & & \\
\hline$<500$ birr & 13 & 45 & 0.000 \\
\hline$\geq 500$ birr & 19 & 10 & \\
\hline History of Induced abortion & & \\
\hline Yes & 1 & 4 & 0.515 \\
\hline No & 28 & 54 & \\
\hline
\end{tabular}

The result of current study showed that education has a significant effect on awareness of EC methods ( $\mathrm{P}<0.05)$. Those women who had secondary education \& above had better awareness than those who attended primary education and illiterates. This may result from the fact that educated people are much more concerned about their health than non-educated people; and easily gather information in this regard. ${ }^{23}$ It is consistent with the conclusion made by different researchers that once a woman enters the school system, her attitude towards family planning changes and that literacy improve one's access to information and provides a sense of trust in science and technology. ${ }^{24}$

Around $64.4 \%$ of the interviewed females were practicing family planning methods. But utilization of EC is very low $(6.9 \%)$ as compared with other contraception methods. It is evident from the present study that the participants' awareness pertaining to EC was also low (28.7\%) there by being a possible reason for its limited utilization. Almost comparable utilization finding was reported from the study conducted in Addis Ababa, Ethiopia, on Ethiopian females aged 15-49 years attending the Ethiopian Immigration and nationality affairs office (EINAO), only $9.3 \%$ of those who were sexually active had ever used ECs to prevent unintended pregnancy. And the major reported reason, $65.6 \%$, for not utilizing EC was lack of knowledge. ${ }^{25}$ According to the study conducted in Ghana $39.9 \%$ of the participants who 
had awareness have ever used ECPs which is higher as compared with our finding. ${ }^{26}$ It could be also the effect of time dependent factors such as media expansion and access to different reproductive health services as well as internet services. Another study conducted in India also reported only $19.6 \%$ of the women who had ever heard of EC had adequate knowledge of it, and $15.1 \%$ of these had ever used EC. ${ }^{27}$ These findings may imply that having adequate knowledge about a given product positively influences utilization of that product.

Our study also identified that those women with relatively good family income have better awareness about EC than those with low family income $(\mathrm{P}<0.05)$. This may be due to the fact that good income widens the social interaction which in turn help them to acquire more information regarding family planning services including EC methods. The same finding was reported from study conducted in Addis Ababa, on women attending ANC at different health centers. ${ }^{28}$ According to our study there is no significant association between awareness and utilization of EC with religion. Study conducted in Ghana also reported that religious unacceptability did not hinder the use of ECPs. ${ }^{26}$

Study participants also reported their concern regarding EC like negative effect on health, hurt the fetus if it doesn't work and also may result in problem to get pregnant in the future. From this it is evident that there is knowledge gap regarding advantages and disadvantages of emergency contraceptives. So there is a need to provide enough information about ECs to help them use contraceptives as well as recommend it to be used by others. From the study conducted in India the most common barriers to using EC were inadequate knowledge of it, it's perceived non-availability, considering it abortifacient and religious beliefs. ${ }^{27}$ Another study in India also reported the most common reason for nonpractice of contraception as fear of side effects of Ecs. ${ }^{29}$

\section{Limitations}

Investigators believe that small sample size was one of the limitations of this study. Self-reporting was used as the only method of measuring knowledge, attitude and use of EC. This method has the disadvantages of recall bias and eliciting only socially acceptable responses and hence, may lead to overestimation of the results.

\section{CONCLUSION}

The study finding showed that the knowledge of EC is low and few number of study participants were aware about EC as well as its advantages and disadvantages. In addition, utilization of EC is also very low. Family income and educational status of the study subjects were identified as barriers affecting the utilization of emergency contraceptives. Further studies should be done on EC with wider study area and there by including more number of study population.

\section{ACKNOWLEDGEMENTS}

We are grateful to Jimma University for funding this study and study participants for their cooperation.

Funding: No funding sources

Conflict of interest: None declared

Ethical approval: The study was approved by the institutional ethics committee

\section{REFERENCES}

1. Ramathuba DU, Khoza LB, Netshikweta ML. Knowledge, attitudes and practice of secondary schools girls towards contraception in Limpopo Province. Curationis 2012;35(1):7 pages.

2. Lakshmi GV, Radha PK, Naidu SA. Knowledge, attitude and practices of EC among female medical students of Andhra Medical College. Int $\mathrm{J}$ Res Health Sci. 2014;2(2):507-10.

3. Fauzia N, Javed I, Aarif T, Khan S, Mamoon A. EC: knowledge, attitudes and practices of General Practitioner. Biomedica. 2004;20.

4. Santosh MB. A survey of knowledge and perceptions towards emergency contraceptives among women of Bijapur, South India. Int J Pharm Bio Sci. 2013;4(1):583-7.

5. World Health Organization (WHO). Unsafe Abortion; Global and regional estimates of the incidence of unsafe abortion and associated mortality in 2003. 5th edition.

6. Koki A. Family Planning and Reproductive Health. Why the United States Should Care. Council on Foreign Relations, 2011.

7. Abrha S, Zeratsion F, Molla F, Eticha T, Assen A, Melkam W. Assessment of Knowledge, Attitude and Practice among Regular Female Preparatory School Students towards Emergency Contraceptives in Mekelle, Northern Ethiopia. IJPSR. 2014;5(11):856-64.

8. Kassa A, Wolde-Mariam M. Knowledge, attitude and practice of emergency contraceptive pills among female students of Hosanna College of Health Sciences, Hosanna, South Ethiopia. JCPS. 2014;7(3):185-93.

9. Central Statistical Authority (CSA) and MACRO Ethiopia Demographic and Health Survey 2005 preliminary report. Calverton, Maryland, U.S.A, 2005.

10. International Consortium for EC, 2004. EC pills: medical and service delivery Guidelines. Second edition.

11. Tesfaye T, Tilahun T, Girma E. Knowledge, attitude and practice of emergency contraceptive among women who seek abortion care at Jimma University specialized hospital, southwest Ethiopia. BMC Women's Health. 2012;12:3.

12. Abate M, Assefa N, Alemayehu T. Knowledge, Attitude, Practice, and Determinants Emergency Contraceptive Use among Women Seeking 
Abortion Services in Dire Dawa, Ethiopia. PLoS One. 2014;9(10).

13. EC in India http://www.plannedparenthood.org/ library/birthcontrol/emergcontra.htm. Accessed 30 Jun 2015.

14. Gold E. EC in Ethiopia: Provider and User Attitudes and Behaviors. Executive Summary. DKT international. http://www.dktinternational.org/wpcontent/uploads/2012/02/DKT-Ethiopia-PostPillWhite-Paper.pdf accessed 30 Jun 2015

15. Chris P. Adolescents and Emergency Contraceptive Pills in Developing Countries. Family health international working paper series. 2005:1-14.

16. Williams K. Provider-related Barriers to Accessing EC in Developing Countries: A Literature Review. https://www.k4health.org/toolkits/emergencycontraception/provider-related-barriers-accessingemergency-contraception. Accessed 30 Jun 2015.

17. Singh V, Thakur P, Nayak PK, Agrawal S. Knowledge attitude and practice (KAP) of emergency contraceptive pills among women of reproductive age group attending AIIMS OPD Raipur (C.G.). Int J Adv Med. 2014;1(2):105-12.

18. Santos OA, Borges A L, Chofakian CBN, Pirotta KM. Determinants of EC non-use among women in unplanned or ambivalent pregnancies. Rev. esc. enferm. USP vol.48 no. spe São Paulo Aug. 2014 Epub Aug 2014 http://dx.doi.org/10.1590/S0080623420140000600003

19. Lemma DA. EC in Addis Ababa: Practice of Service Providers. University Of South Africa 2009.

20. Gold E. DKT Ethiopia's Postpill emergency contraceptive. An Asseessment of provider and customer attitudes and behaviors. DKT Ethiopia. March 2011. http://www.dktethiopia.org/sites/ default/files/PublicationFiles/Emergency_Contracep tive_Assessment_0.pdf. Accessed 30 Jun 2015.

21. PATH. Client Knowledge, Attitudes, and Practices Questionnaire. http://www.path.org/ publications/ files/ RH_ec_module_e.pdf. Accessed 30 Jun 2015

22. Tajure N. Knowledge, Attitude and Practice of EC among Graduating Female Students of Jimma
University, Southwest Ethiopia. Ethiop J Health Sci. 2010;20(2):91-7.

23. Ahmed FA, Moussa KM, Petterson KO, Asamoah BO. Assessing knowledge, attitude, and practice of EC: a cross- sectional study among Ethiopian undergraduate female students. BMC Public Health. 2012;12:110.

24. Worku A. Knowledge, attitude and practice of emergency contraceptives among female college students in Arba Minch Town, Southern Ethiopia. Ethiop. J. Health Dev. 2011;25(3):177-83.

25. Bugssa G, Kahsay T, Asres A, Dimtsu B, Tsige Y. Factors Associated with Knowledge, Attitude and Practice towards EC among Female Clients of Ethiopian Immigration and Nationality Affairs Office. J Community Med Health Educ. 2014;4:305.

26. Anthony A, Victor M, Appiah MNA, Winnifred A M. Awareness, use and associated factors of emergency contraceptive pills among women of reproductive age (15-49 years) in Tamale, Ghana. BMC Women's Health. 2014;14:114.

27. Hafizur R, Ezzat K, Sumit K, Latha K. Knowledge of, attitudes toward, and barriers to the practice of EC among women in Sikkim, India. IJGO. 2013;122(2):99-103.

28. Etalemahu D Assessment of barriers of EC use among antenatal care clients of Addis Ababa health centres. Addis Ababa University Libraries Electronic Thesis and Dissertations: AAU-ETD, Faculty of medicine: Thesis-public health 2007.

29. Anupama S, Mohammad SK, Chitra RC. Knowledge, Attitude and Practices about Contraceptive among Married Reproductive Females. International Journal of Scientific Study. 2014;1(5):1-4.

Cite this article as: Seifu M, Gashe F, Jemal A, Tessema S, Amelo W. Assessment of the knowledge, attitude and practice of EC and barriers to its use among the antenatal care seekers of Sululta Health Centers, Oromia region, Ethiopia. Int J Sci Rep 2016;2(2):29-35. 